\title{
An Interesting Case of Post-fundoplication Dysphagia
}

\author{
Mayank Jain
}

Department of Gastroenterology, Choithram Hospital and Research Center, Indore, India

A 40-year-old male patient, who had undergone laparoscopic fundoplication for hiatus hernia 2 years ago, presented with history of dysphagia for solids for 18 months and weight loss of 12 $\mathrm{kg}$ over last 18 months. The dysphagia was persistent, severe, affected by food intake and was associated with chest pain. He was prescribed proton pump inhibitors and underwent 2 sessions of esophageal dilatation up to $15 \mathrm{~mm}$ balloon but had no relief of symptoms. High-resolution manometry (Figure) revealed a high resting basal lower esophageal sphincter (LES) pressure (48 $\mathrm{mmHg}$ ) with high mean integrated relaxation pressure (49.2 $\mathrm{mmHg}$ ). Esophageal peristalsis was normal in 6/10 wet swallows and showed weak peristalsis with small/large breaks in $4 / 10$ swallows. A sudden increase was noted in the LES pressure up to $300 \mathrm{mmHg}$ after each wet swallow. A diagnosis of hypertensive LES with impaired esophagogastric junction relaxation was made.

Laparoscopic fundoplication is a commonly performed surgery. Common late post-operative complications include gas-bloat syndrome (up to $85 \%$ ), dysphagia (10-50\%), diarrhea (18-33\%), and recurrent heartburn (10-62\%). ${ }^{1}$ Kahrilas et $\mathrm{al}^{2}$ reported that fundoplication limits the axial mobility of the esophagogastric junction and causes restricted hiatal opening. Sato et $\mathrm{al}^{3}$ reported a post-operative dysphagia rate of $6 \%$ and the main causes were inaccurate preoperative endoscopy, hiatal stenosis secondary to severe fibrotic reaction, anterior angulation of the gastroesophageal junction, missed diagnosis of the short esophagus, nutcracker esophagus and a too tight fundoplication. O'Brein et $\mathrm{al}^{4}$ reported 2 cases of esophageal dysmotility which were not evaluated prior to surgery and had post-fundoplication dysphagia.

In this patient, severe post-operative dysphagia is probably linked to severe fibrosis and inadequate preoperative workup for

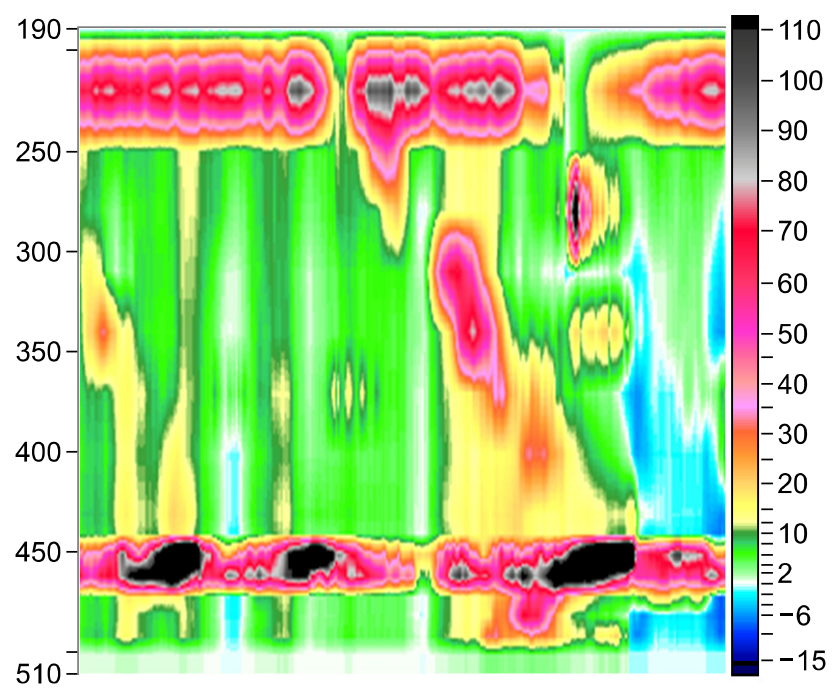

Figure. Manometric recording of the patient.

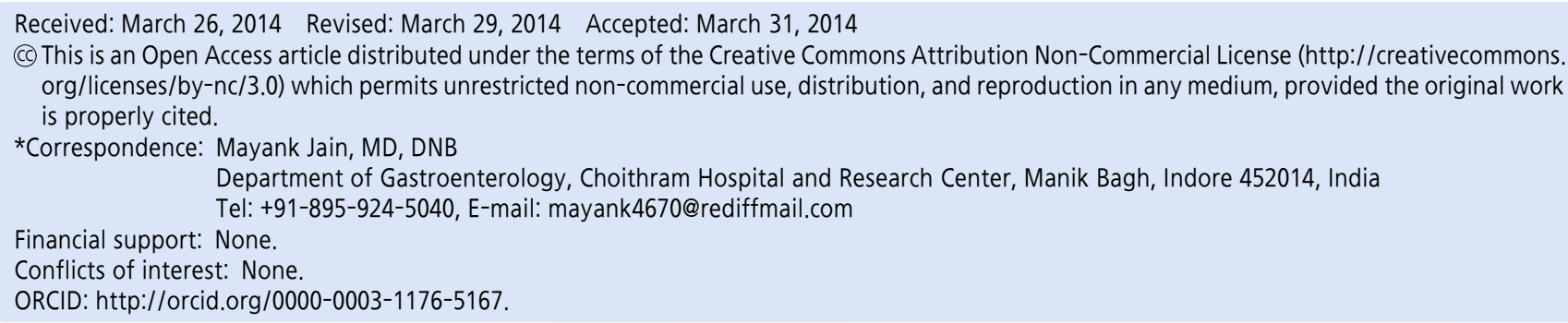


dysmotility. The patient denies history of dysphagia for 6 months after surgery and so it appears unlikely to be due to a tight fundoplication. The patient has been advised dilatation using balloon and if there is insufficient relief, a revision surgery.

\section{References}

1. Richter JE. Gastroesophageal reflux disease treatment: side effects and complications of fundoplication. Clin Gastroenterol Hepatol 2013;11:465-471.

2. Kahrilas PJ, Lin S, Spiess AE, Brasseur JG, Joehl RJ, Manka M. Impact of fundoplication on bolus transit acrossesophagogastric junction. Am J Physiol 1998;275(6 Pt 1):G1386-G1393.

3. Sato K, Awad ZT, Filipi CJ, et al. Causes of long-term dysphagia after laparoscopic Nissen fundoplication. JSLS 2002;6:35-40.

4. O'Brien CJ, Collins JS, Collins BJ, McGuigan J. Aperistaltic oesophageal disorders unmasked by severe post-fundoplication dysphagia. Postgrad Med J 1991;66:1047-1049. 